\title{
The Impact of COVID-19 on Missed Ophthalmology Clinic Visits
}

\author{
Arthur R Brant ${ }^{\prime}$ \\ Suzann Pershing ${ }^{1,2}$ \\ Olivia Hess' \\ David Rooney' \\ Jeffrey Goldberg' \\ Geoffrey Tabin ${ }^{1,2}$ \\ Sophia Y Wang $\mathbb{D}^{\prime}$
}

'Byers Eye Institute, Stanford University, Stanford, CA, USA; ${ }^{2}$ VA Palo Alto Health

Care System, Palo Alto, CA, USA
Correspondence: Arthur R Brant

Tel + I 3306517898

Email abrant@Stanford.edu
Purpose: To measure the COVID-19 pandemic impact on missed ophthalmology clinic visits and the influence of patient and eye disease characteristics on likelihood of missing clinic visits before and during the pandemic.

Patients and Methods: A retrospective observational study analyzing eye clinic patients at a large tertiary care academic institution. We identified patients scheduled for eye care during pre-COVID-19 (January 1-February 29, 2020) and early COVID-19 (March 16-May 31, 2020) time periods. Missed appointment frequency and characteristics were evaluated during each time period. Multivariable logistic regression models were developed to examine adjusted odds of having at least one missed appointment during a given time period. Covariates included age, sex, race/ethnicity, marital status, preferred language (non-English vs English), insurance, distance from clinic, and diagnosis.

Results: Overall, $82.0 \%(n=11,998)$ of pre-COVID-19 patients completed all scheduled visits, compared to only 59.3\% $(\mathrm{n}=9020)$ during COVID-19. Missed visits increased dramatically in late March 2020, then improved week by week through the end of May 2020. General ophthalmology/cataract and strabismus clinics had the highest rates of missed clinic visits during the COVID-19 period; neuro-ophthalmology, retina, cornea, oculoplastics and glaucoma had the lowest. Females, Blacks, Hispanics, Asians, ages 50+, and married patients had higher adjusted odds of missing clinic visits, both pre-COVID-19 and during COVID-19. Asian, elderly, and cataract patients had the highest adjusted odds of missing clinic visits during COVID-19 and had significant increases in odds compared to pre-COVID-19. Non-married, diabetic macular edema, and wet age-related macular degeneration patients had the lowest adjusted odds of missed visits during COVID-19.

Conclusion: Missed clinic visits increased dramatically during the COVID-19 pandemic, particularly among elderly and nonwhite patients. These findings reflect differences in eye care delivery during the pandemic, and they indicate opportunities to target barriers to care, even during non-pandemic eras.

Keywords: COVID-19, healthcare utilization, disparities

\section{Introduction}

The COVID-19 pandemic has brought significant stress to the US healthcare system, impacting patients' abilities to access urgent and elective care, and decreasing volumes of surgeries, hospital admissions, and clinic visits. ${ }^{1-3}$ To reduce risks for COVID-19 transmission and to conserve hospital resources, many regions implemented restrictions on population movement ("shelter-in-place" orders) and restrictions on elective care early in the pandemic, ${ }^{4}$ and patients likewise cancelled or deferred clinical care. On March 18th 2020, the American Academy of 
Ophthalmology issued guidance "that all ophthalmologists cease providing any treatment other than urgent or emergent care immediately". 5

With a high volume of elective procedures, ophthalmology has been reported to be one of the fields most impacted by COVID-19, losing $81 \%$ of patient volume in March and April of $2020 .^{6}$ Since the start of the COVID19 pandemic, the ophthalmology community has been closely monitoring and discussing the impact of the pandemic on ophthalmology care, anticipating and reacting to changes in virtual care, elective surgery restrictions, and non-physician provider regulations. ${ }^{1}$ Around the world, ophthalmologists have reported a $56 \%$ drop in cornea transplants in Italy and cataract surgeries were postponed for three months at Moorfield's Eye Hospital. ${ }^{7,8}$ As the ophthalmology community continues to balance providing care with mitigating risk to patients and providers, it is important to understand possible disproportionate impacts on care for different patient populations. ${ }^{9}$ For example, job losses related to COVID-19 and economic turmoil have hindered patients' access to health insurance and other resources, ${ }^{10}$ especially patients of racial and ethnic minorities. ${ }^{11}$ Although several news and academic publications have made qualitative observations and projections on the impact of COVID-19 in ophthalmology, ${ }^{12,13}$ few have conducted detailed quantitative analyses on patient care and patient outcomes. Here we investigate the magnitude of missed clinic visits, focusing on patient and disease characteristics associated with missing visits in the earliest phases of the pandemic, corresponding to the time period of strictest initial restrictions. We use data from a large tertiary care academic institution in California, one of the states most affected by COVID-19.

\section{Methods}

\section{Cohort}

We evaluated adult patients receiving care at the Byers Eye Institute at Stanford University School of Medicine, a large tertiary care academic institution in California. Santa Clara County, where the Byers Eye Institute is located, issued shelter in place orders on March 17th, 2020, ${ }^{14}$ and California issued state-wide shelter in place orders on March 19th, 2020. ${ }^{15}$ All elective clinical care was deferred per policy between the week of March 16, 2020, and reopened formally May 4, 2020, and many patients also selfcancelled or deferred scheduled clinic visits. ${ }^{16}$ We used these dates to identify patients scheduled for care between
March 16th, 2020 (California's first shelter-in-place) and May 31st 2020 ("COVID-19 period"), as well as those scheduled for care between January 1st and February 29th 2020 ("pre-COVID-19 period" for comparison). Within each respective time period, clinical data on both completed and missed clinic visits were collected from the Stanford electronic health record (Epic Systems, Verona, Wisconsin). The study was approved by Stanford's IRB, consent was obtained by all participants, and the guidelines outlined in the Declaration of Helsinki were followed.

\section{Patient Characteristics}

Patient characteristics were collected using the Stanford Research Repository (STARR) ${ }^{17}$ Clinical Data Warehouse, including age, gender, race/ethnicity, insurance type, marital status, and address. Patient zipcode was used to calculate the approximate home-to-clinic commute time using the Google Maps API ${ }^{18}$ and also the approximate socioeconomic-status using average zipcode household incomes as determined by 2018 Internal Revenue Service (IRS) data. ${ }^{19}$ For patients who were seen for at least one clinic visit during the COVID-19 or pre-COVID-19 time periods, ophthalmic disease diagnoses were determined by the diagnosis codes associated with the clinic visits. For patients who had no completed clinic visits during a given time period, diagnoses were determined from the three most recent ophthalmology clinic encounters. Common diagnoses were grouped into broad categories as follows: diabetic macular edema (DME), diabetic retinopathy (DR), wet age-related macular degeneration (wet AMD), dry or unspecified AMD, cataract, glaucoma, and pseudophakia or aphakia (Supplemental Table 1); all other diagnoses were not analyzed separately. Patients with multiple diagnoses would be included in multiple categories.

\section{Clinic Visit Characteristics}

A missed clinic visit was defined as a cancelled, rescheduled or no-show clinic visit with failure to complete at least one originally scheduled visit within 7 days of that original date. We allowed a seven-day window for clinic visit completion because many ophthalmology providers consolidated clinic sessions into a smaller number of clinic days each week during the COVID-19 period, and most rescheduled visits occurred within 7 days of the initial missed appointment (Supplemental Figure 1). Thus, a patient was considered to have completed all clinic visits if they completed a visit within a week of each scheduled visit (including in-person as well as face-to-face visits), 
and a clinic visit was considered to be "missed" if it was not rescheduled and completed within one week. Visits were counted as completed even if originally scheduled as face-to-face but completed as telehealth visits. Characteristics of missed clinic visits included whether or not a miss that occurred during the COVID-19 period was documented as due to a COVID-19-related reason (eg, patient illness or fear of transmission). This was determined through manual review of the missed clinic visit reports, which provided codes indicating these characteristics as well as free-text notes made by the staff person who cancelled the appointment. The type of clinic visit (new patient visit versus returning patient visit) and the ophthalmology provider subspecialty were also obtained.

\section{Statistical Analysis}

The main outcome of interest was whether a patient completed all scheduled clinic visits or missed at least one clinic visit in each respective time period (COVID-19 and pre-COVID-19). We examined the association of patient and clinic encounter characteristics with missed clinic visits. All statistical analyses were conducted using Python 3.0 (Python Software Cooperation, Wilmington, DE, USA). Chi-squared tests were used to compare categorical variables and $t$-tests were used for continuous variables. Multivariable logistic regression analysis was used to examine the impact of patient characteristics on adjusted odds of having at least one missed appointment vs no missed appointments (out of all patients who ever had an appointment scheduled during a given time period). Covariates included age, gender, race/ethnicity, marital status, preferred language (non-English vs English), type of insurance (Medicare, Medicaid, private, other), distance from the clinic, and diagnosis. In aggregate logistic regression analysis across both time periods, we evaluated an interaction term for each covariate interacted with time period, to assess whether each of the above covariates had a differential effect on missing clinic visits during COVID-19 vs pre-COVID time periods. Since multiple interaction terms were significant, we stratified our regression analyses into COVID-19 and pre-COVID -19 periods to measure the respective effect of each predictor on odds of missing at least one clinic visit during each period.

\section{Results}

\section{Patient Characteristics and Timeline of Missed Clinic Visits}

In the January 1-February 29, 2020 pre-COVID period (including holiday weeks), 14,635 unique patients were seen over 44,153 visits ( $91.6 \%$ of scheduled visits), with 4057 missed clinic visits recorded $(8.4 \%$ of scheduled visits). By contrast, in the March 16-May 31, 2020 COVID period, 15,224 unique patients were seen over 33,919 visits $(76.5 \%$ of scheduled visits), with 10,412 missed clinic visits recorded (23.5\% of scheduled visits). Collapsing the data analysis from unique visits to unique patients, characteristics of patients who completed all scheduled visits ("Completed Visits") or had at least one missed visit not rescheduled within 7 days ("Missed Visits") are described in Table 1. Overall, 82.0\% ( $\mathrm{n}=$ $11,998)$ of patients in the pre-COVID-19 period completed all scheduled visits $(18.0 \%$ had at least one missed appointment), whereas $59.3 \%(\mathrm{n}=9020)$ of patients during the COVID-19 period completed all scheduled visits (40.7\% had at least one missed appointment) (Table 1).

Missed clinic visits began trending upward on March 2nd and peaked on the week of March 23rd (Figure 1A), when only 490 visits $(22.4 \%$ of scheduled visits) were completed. The completion rate then increased from March 23rd to May 31st, a week in which 995 visits (55.9\% of scheduled visits) were completed. Among all specialties, general ophthalmology/cataract and strabismus clinics had the lowest completion rates during the COVID19 period; neuro-ophthalmology, retina, cornea, oculoplastics and glaucoma had the highest completion rates (Figure 1A). Completion rates of new and return patients were similar (Figure 1B). Among all 15,703 total missed visits (which included some patients with multiple missed visits), 9308 (59.3\%) had documented reasons for missing visits. COVID-19 was the reason for $61.7 \%$ of all missed visits in March, $89.6 \%$ of those in April, and $80.0 \%$ of those in May (Figure 2).

\section{Patient Factors Associated with Missed Visits}

In the pre-COVID-19 time period, black race was associated with the highest frequency of missed appointments compared to other patient characteristics $(26.0 \%$ of black patients had at least one missed appointment). However, during the COVID-19 time period, Asian patients had highest percentage of missed appointments $(51.3 \%$ of Asian patients had at least one missed appointment). Among patients with reported race/ethnicity, Hispanic patients had the lowest frequency of missed appointments in both pre-COVID-19 (16.3\%) and COVID-19 (34.8\%) time periods. Asian, married, and Medicare-insured 
Table I Characteristics of Patients in the Pre-COVID-19 and COVID-19 Time Periods Based on Missed Visit Status ${ }^{\mathrm{a}}$

\begin{tabular}{|c|c|c|c|c|c|}
\hline & \multirow{4}{*}{$\begin{array}{l}\text { Pre-COVID-I } 9 \\
\text { Period } \\
\text { N (\%) of Patients } \\
\text { with No Missed } \\
\text { Visits }^{\text {b }}\end{array}$} & \multirow{4}{*}{$\begin{array}{l}\text { COVID-19 } \\
\text { Period } \\
\text { N (\%) of } \\
\text { Patients with } \\
\text { No Missed } \\
\text { Visits }^{\mathrm{a}}\end{array}$} & \multirow{4}{*}{$\begin{array}{l}\text { Difference in \% } \\
\text { Missed Visits } \\
\text { COVID-I9 Period } \\
\text { vs Pre-COVID-I9 } \\
\text { Period }\end{array}$} & \multicolumn{2}{|c|}{ Tests of Statistical Significance } \\
\hline & & & & \multirow{2}{*}{$\begin{array}{l}\text { Missed Visits in Pre- } \\
\text { COVID-19 vs COVID- } \\
19 \text { Period }^{\mathrm{c}}\end{array}$} & \multirow{2}{*}{$\begin{array}{l}\text { Completed vs } \\
\text { Missed Visits in } \\
\text { CoVID-19 } \text { Period }^{\mathrm{d}}\end{array}$} \\
\hline & & & & & \\
\hline & & & & p-value & p-value \\
\hline Total & $14,635(81.98 \%)$ & 15,224 (59.25\%) & $-22.73 \%$ & & \\
\hline Sex & & & & $<0.001$ & 0.242 \\
\hline Male & $6268(83.77 \%)$ & 6747 (61.39\%) & $-22.38 \%$ & & \\
\hline Female & 7687 (80.84\%) & $8175(56.43 \%)$ & $-24.41 \%$ & & \\
\hline Missing & 679 (78.35\%) & 299 (88.29\%) & $9.94 \%$ & & \\
\hline Race/Ethnicity & & & & $<0.001$ & 0.003 \\
\hline White & $5098(82.29 \%)$ & $540 \mathrm{I}(55.99 \%)$ & $-26.3 \%$ & & \\
\hline Black & 361 (73.96\%) & $392(54.59 \%)$ & $-19.37 \%$ & & \\
\hline Asian & $3242(79.73 \%)$ & $3402(48.71 \%)$ & $-31.03 \%$ & & \\
\hline Hispanic & $2178(83.75 \%)$ & $2344(65.23 \%)$ & $-18.52 \%$ & & \\
\hline Other & $1602(78.7 \mid \%)$ & 1651 (55.91\%) & $-22.81 \%$ & & \\
\hline Missing & $2154(86.63 \%)$ & $2034(82.25 \%)$ & $-4.38 \%$ & & \\
\hline Age & & & & $<0.001$ & $<0.001$ \\
\hline Age $<50$ years & $5426(87.08 \%)$ & $5980(75.37 \%)$ & $-11.71 \%$ & & \\
\hline Age $50-64$ years & $2761(76.35 \%)$ & $2840(51.06 \%)$ & $-25.29 \%$ & & \\
\hline Age $65-74$ years & $2800(78.82 \%)$ & 2876 (45.9\%) & $-32.92 \%$ & & \\
\hline Age $75-84$ years & 2036 (8I.53\%) & 2240 (45.85\%) & $-35.68 \%$ & & \\
\hline Age $85+$ years & 933 (82.1\%) & 989 (45.7\%) & $-36.4 \%$ & & \\
\hline Language & & & & 0.401 & 0.107 \\
\hline English & |2,038 (81.9|\%) & $12,9 \mid 4$ (58.84\%) & $-23.07 \%$ & & \\
\hline Other & 1906 (83.95\%) & I99| (57.8I\%) & $-26.14 \%$ & & \\
\hline Missing & 691 (77.86\%) & 319 (84.95\%) & $7.09 \%$ & & \\
\hline Married & & & & $<0.001$ & 0.029 \\
\hline Married & 7024 (79.9\%) & 7204 (49.15\%) & $-30.74 \%$ & & \\
\hline Not married & $6920(84.54 \%)$ & $7700(67.58 \%)$ & $-16.95 \%$ & & \\
\hline Missing & 691 (77.57\%) & 320 (85.94\%) & $8.37 \%$ & & \\
\hline Diagnosis & & & & $<0.001$ & 0.089 \\
\hline DME & 477 (79.45\%) & 559 (54.92\%) & $-24.54 \%$ & & \\
\hline Wet AMD & 409 (77.75\%) & 455 (53.19\%) & $-24.56 \%$ & & \\
\hline
\end{tabular}

(Continued) 
Table I (Continued).

\begin{tabular}{|c|c|c|c|c|c|}
\hline & \multirow{4}{*}{$\begin{array}{l}\text { Pre-COVID-I9 } \\
\text { Period } \\
\text { N (\%) of Patients } \\
\text { with No Missed } \\
\text { Visits }^{\text {b }}\end{array}$} & \multirow{4}{*}{$\begin{array}{l}\text { COVID-I9 } \\
\text { Period }\end{array}$} & \multirow{4}{*}{$\begin{array}{l}\text { Difference in \% } \\
\text { Missed Visits } \\
\text { COVID-I9 Period } \\
\text { vs Pre-COVID-19 } \\
\text { Period }\end{array}$} & \multicolumn{2}{|c|}{ Tests of Statistical Significance } \\
\hline & & & & \multirow{2}{*}{$\begin{array}{l}\text { Missed Visits in Pre- } \\
\text { COVID-19 vs COVID- } \\
19 \text { Period }^{c}\end{array}$} & \multirow{2}{*}{$\begin{array}{l}\text { Completed vs } \\
\text { Missed Visits in } \\
\text { COVID-19 Period }^{\mathrm{d}}\end{array}$} \\
\hline & & & & & \\
\hline & & & & p-value & p-value \\
\hline $\begin{array}{l}\text { Dry/Unspecified } \\
\text { AMD }\end{array}$ & 909 (79.21\%) & $1042(43.28 \%)$ & $-35.93 \%$ & & \\
\hline Cataract & $3816(78.85 \%)$ & 4587 (42.66\%) & $-36.19 \%$ & & \\
\hline $\begin{array}{l}\text { Pseudophakia or } \\
\text { Aphakia }\end{array}$ & $2177(80.02 \%)$ & $2748(44.32 \%)$ & $-35.7 \%$ & & \\
\hline Cataract & $3816(78.85 \%)$ & $4587(42.66 \%)$ & $-36.19 \%$ & & \\
\hline \multicolumn{6}{|l|}{ Glaucoma } \\
\hline Mild glaucoma & 411 (80.29\%) & 531 (45.95\%) & $-34.34 \%$ & & \\
\hline Moderate glaucoma & $520(82.69 \%)$ & 627 (50.08\%) & $-32.61 \%$ & & \\
\hline Severe glaucoma & 444 (79.5\%) & 567 (49.56\%) & $-29.95 \%$ & & \\
\hline $\begin{array}{l}\text { Unspecified } \\
\text { glaucoma }\end{array}$ & 986 (82.45\%) & II 52 (5I.48\%) & $-30.98 \%$ & & \\
\hline \multicolumn{6}{|l|}{ Diabetic retinopathy } \\
\hline Mild DR & I7| (79.53\%) & $230(44.78 \%)$ & $-34.75 \%$ & & \\
\hline Moderate DR & $73(82.19 \%)$ & 105 (54.29\%) & $-27.91 \%$ & & \\
\hline Severe DR & $52(75.0 \%)$ & $66(48.48 \%)$ & $-26.52 \%$ & & \\
\hline Proliferative DR & 188 (75.53\%) & $222(55.41 \%)$ & $-20.13 \%$ & & \\
\hline Distance from Clinic & & & & $<0.001$ & $<0.001$ \\
\hline$<20 \mathrm{~km}$ & 4707 (84.49\%) & 4961 (55.84\%) & $-28.66 \%$ & & \\
\hline $20-49 \mathrm{~km}$ & $5190(80.92 \%)$ & $5566(57.1 \%)$ & $-23.83 \%$ & & \\
\hline $50-149 \mathrm{~km}$ & $2610(81.38 \%)$ & $2900(63.83 \%)$ & $-17.55 \%$ & & \\
\hline $150-299 \mathrm{~km}$ & 863 (80.76\%) & 895 (65.81\%) & $-14.95 \%$ & & \\
\hline$>300 \mathrm{~km}$ & $514(79.38 \%)$ & $520(59.62 \%)$ & $-19.76 \%$ & & \\
\hline Insurance & & & & $<0.001$ & $<0.001$ \\
\hline Private & $5138(82.74 \%)$ & $5696(64.33 \%)$ & $-18.41 \%$ & & \\
\hline Medicare & 4852 (80.36\%) & 5207 (46.36\%) & $-34.0 \%$ & & \\
\hline Medicaid & $2316(85.06 \%)$ & $2513(72.54 \%)$ & $-12.52 \%$ & & \\
\hline Other & $218(76.61 \%)$ & 227 (56.83\%) & $-19.78 \%$ & & \\
\hline Income & & & & $<0.001$ & $<0.001$ \\
\hline$<\$ 20,000$ & $2215(83.75 \%)$ & $2358(57.08 \%)$ & $-26.66 \%$ & & \\
\hline
\end{tabular}

(Continued) 
Table I (Continued).

\begin{tabular}{|c|c|c|c|c|c|}
\hline & \multirow{4}{*}{$\begin{array}{l}\text { Pre-COVID-I9 } \\
\text { Period } \\
\text { N (\%) of Patients } \\
\text { with No Missed } \\
\text { Visits }^{\text {b }}\end{array}$} & \multirow{4}{*}{$\begin{array}{l}\text { COVID-19 } \\
\text { Period }\end{array}$} & \multirow{4}{*}{$\begin{array}{l}\text { Difference in \% } \\
\text { Missed Visits } \\
\text { COVID-19 Period } \\
\text { vs Pre-COVID-19 } \\
\text { Period }\end{array}$} & \multicolumn{2}{|c|}{ Tests of Statistical Significance } \\
\hline & & & & \multirow{2}{*}{$\begin{array}{l}\text { Missed Visits in Pre- } \\
\text { COVID-19 vs COVID- } \\
19 \text { Period }^{c}\end{array}$} & \multirow{2}{*}{ 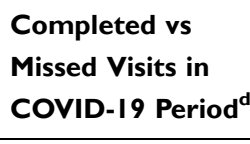 } \\
\hline & & & & & \\
\hline & & & & p-value & p-value \\
\hline$\$ 20,000-\$ 49,999$ & $6190(82.29 \%)$ & $6633(57.35 \%)$ & $-24.94 \%$ & & \\
\hline$\$ 50,000-\$ 99,999$ & $4193(80.87 \%)$ & $4444(60.26 \%)$ & $-20.61 \%$ & & \\
\hline$\$ 100,000+$ & 1029 (82.99\%) & 1129 (65.63\%) & $-17.36 \%$ & & \\
\hline
\end{tabular}

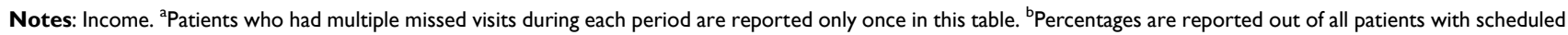
visits in a given time period. Evaluated percentage of all patients with scheduled visits who completed all visits within 7 days of the original scheduled date(s) (ie, no missed visits). Pre-COVID-19 time period is I/I/2020-2/29/2020; COVID-19 is 3/16/20-5/3I/20. ' Comparison of \% missed visits between time periods (pre-COVID-I9 versus COVID-19), based on chi-squared. ${ }^{d}$ Comparison of $\%$ missed visits vs $\%$ completed visits within COVID-1 9 time period, based on chi-squared.

Abbreviations: DME, diabetic macular edema; AMD, age-related macular degeneration; DR, diabetic retinopathy.

patients had the greatest increase in missed appointments between pre-COVID-19 to COVID-19 periods, as did patients who had lower-urgency ophthalmic comorbidities (eg, cataract, dry AMD, mild glaucoma or diabetic retinopathy). During the pre-COVID-19 period, different age groups had similar missed visit frequencies (12.9223.65\%); however, during COVID-19, the missed frequency varied dramatically between $<50$-year-old patients $(24.63 \%)$ and $85+$ patients $(54.3 \%)$ (Table 1$)$.

Similarly, in multivariable logistic regression analysis (Table 2), Asians, older adults, and cataract patients had the highest adjusted odds of missed visits during the COVID-19 period (OR 1.67, 95\% CI 1.52-1.83, p < 0.001 , for Asian compared to white patients; OR 2.62; $95 \%$ CI $2.17-3.15, \mathrm{p}<0.001$ for adults $\geq 85$ years old compared to patients $\leq 50$ years old; OR $1.73,95 \% \mathrm{CI}$ $1.56-1.91, \mathrm{p}<0.001$ for cataract patients compared to those without a cataract diagnosis). DME and wet AMD diagnoses had the lowest adjusted odds of missed visits during COVID-19 (OR 0.77, 95\% CI 0.61-0.98, $\mathrm{p}=0.032$ for DME patients compared to those without DME; OR $0.72,95 \%$ CI $0.57-0.91, p=0.005$ for wet AMD patients compared to those without wet AMD).

Compared to white patients, those of nonwhite race/ethnicity had consistently higher odds of missed visits in both pre-COVID-19 and COVID-19 periods, as did older adults ( $>50$ years of age compared to those 50 years old and younger) and female patients (Table 2). Married patients and those with a cataract diagnosis were also more likely to miss visits across both time periods. Some clinical diagnoses were only statistically significant in the COVID-19 time period, with lower odds of missed visits among patients who carried a DME diagnosis and increased odds among those with a dry AMD, pseudophakia/aphakia, and/or pathologic myopia diagnosis. Medicaid patients were less likely to miss visits during both the pre-COVID-19 and COVID19 period. English speakers were less likely to miss visits pre-COVID-19; however, were more likely to do so during the COVID-19 period. Patient distance from clinic was only statistically significant in the pre-COVID-19 period, with increasing odds of missed visits for patients who lived further away from the clinic. Distance did not have a statistically significant effect during the COVID-19 period. Income did not have a statistically significant association with odds of missed visits in either time period (Table 2). The severity of glaucoma and diabetic retinopathy did not correlate to the odds of missing visits during the pre-COVID-19 or COVID19 period.

There were significant interaction effects between Asian race/ethnicity, marital status, older age, cataract diagnosis, and pathologic myopia, respectively, with pre-COVID-19/ COVID-19 time period, indicating that patients were more likely to miss clinic visits during both pre-COVID-19 and COVID-19 periods, but with greater magnitude during the COVID-19 period. Wet AMD also had a significant interaction with time period; however, wet AMD patients were less likely to miss visits during the COVID-19 time period compared to pre-COVID-19.

\section{Discussion}

In this analysis of ophthalmology patient visits at a large tertiary-care academic medical center in California, we 


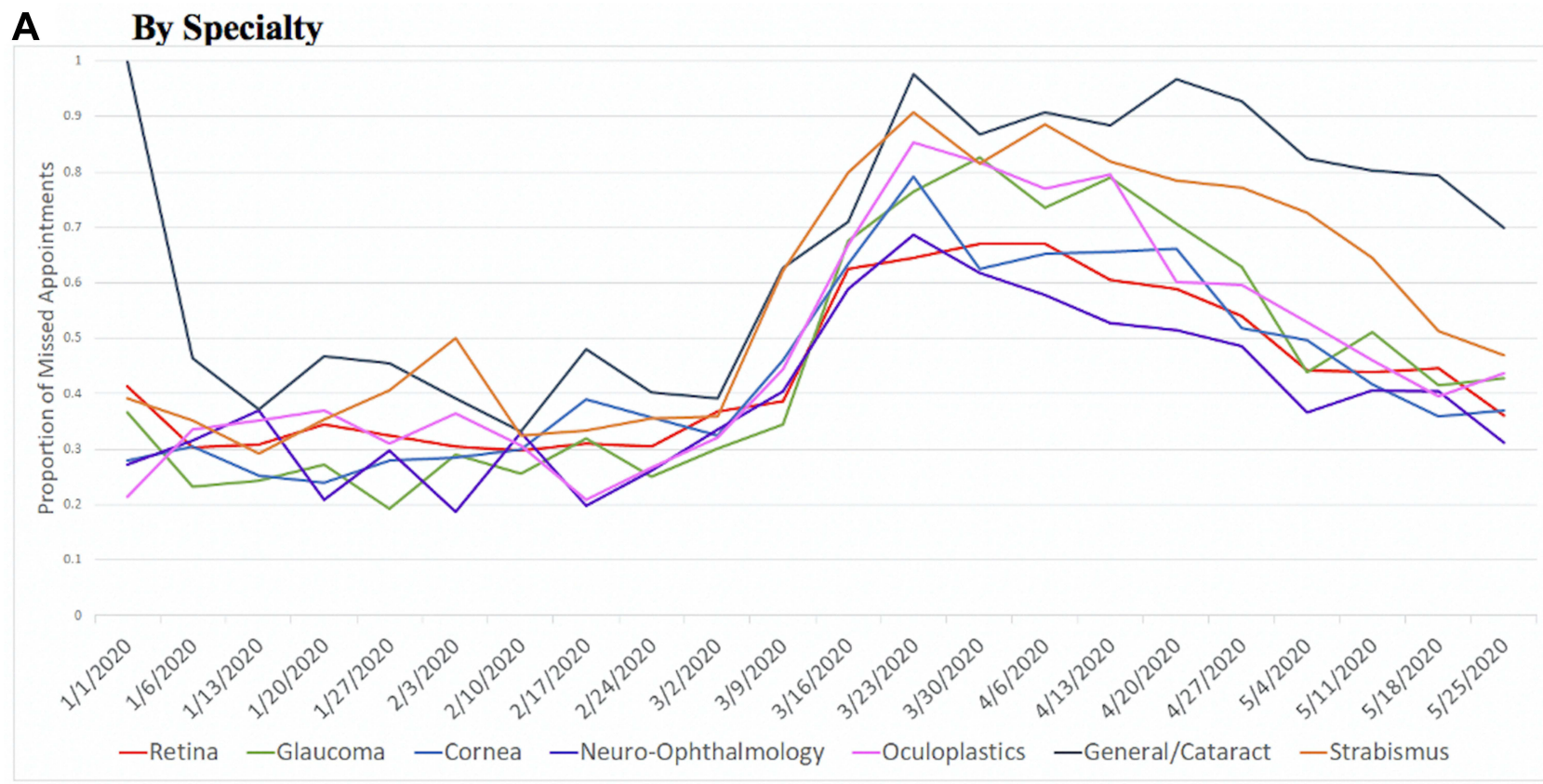

\section{B By Appointment Type}

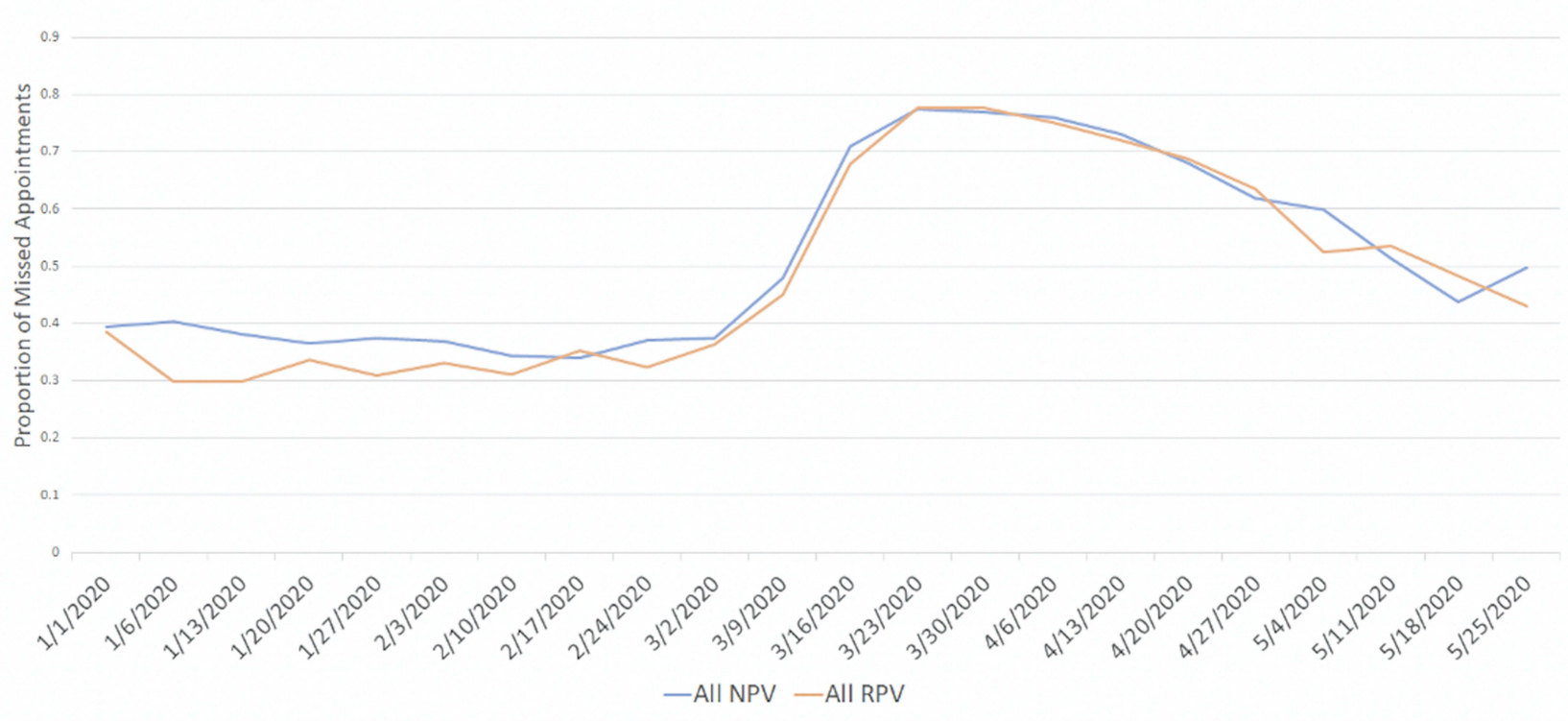

Figure I Timeline of completed and cancelled appointments in 2021. (A) The percentage of weekly appointments cancelled by specialty. (B) The percentage of weekly appointments cancelled by visit type (return or new).

evaluated missed visits during pre-COVID-19 (1/1/20202-29/2020) and COVID-19 (3/16/20-5/31/20) time periods. $40.7 \%$ of patients missed at least 1 clinic visit during the COVID-19 period, compared to $18.0 \%$ of patients in the pre-COVID-19 period. Clinics with general ophthalmology/cataract and strabismus specialists had the highest rates of missed visits during the COVID-19 period. Odds of missing visits in pre-COVID-19 and COVID-19 time periods differed based on patient characteristics. Older, nonwhite, female, married, and patients carrying a cataract diagnosis were more likely to miss visits, especially during the COVID-19 period. Wet AMD and DME patients were less likely to miss visits in the COVID19 period, and although living further away from the clinic 


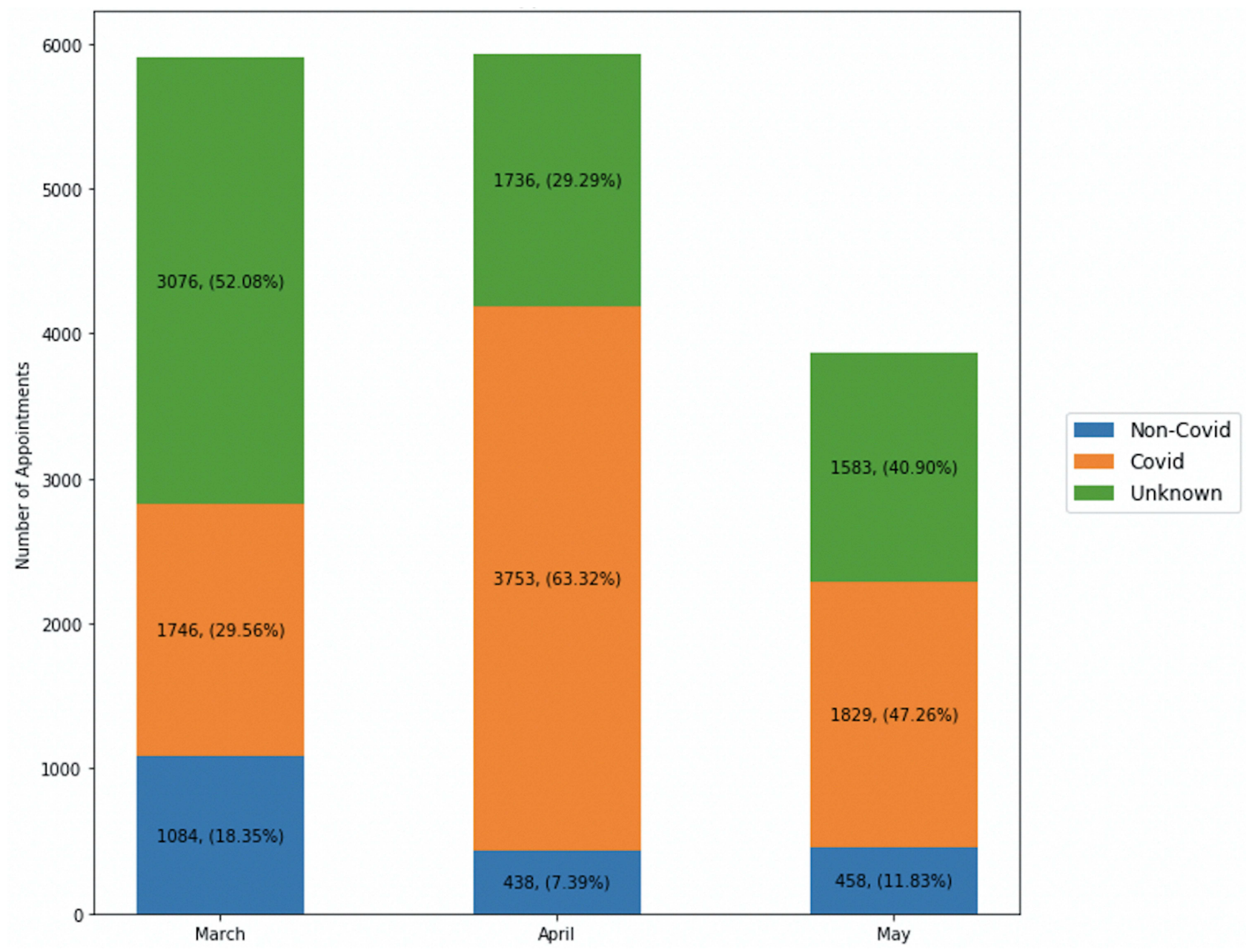

Figure 2 Reason for cancelled appointments during COVID-19 time period.

was associated with higher odds of missed visits preCOVID-19, it ceased to be significant when accounting for other variables in the COVID-19 period.

The rise in missed visits began a few days after California's first state-wide shelter-in-place, which took effect on March 16, 2020. Missed visits increased dramatically in late March 2020, peaking at $78.0 \%$ of visits, and subsequently improved week by week through the end of May, although still not reaching the lower levels seen preCOVID-19. This decreasing frequency of missed visits likely represented a combination of increased patient and provider comfort with clinic adaptations to providing care (eg, masking and distancing protocols), potential for harm from continued deferral of eye care, and fewer scheduled visits overall (ie, emphasizing essential care when scheduling patients). Consistent with this hypothesis, the cited reason for missed visits in April was almost always COVID-19 (89.6\%), which became less common in May.
Missed visits occurred across all subspecialties, but increased most dramatically in clinics for general, cataract, and strabismus providers. This finding reflects a greater ability to defer care in these areas and is consistent with reports from pre-COVID-19 studies. ${ }^{20}$ The breakdown by subspecialty suggests that patients with more time-sensitive pathology and potential for irreversible vision loss (eg, retina, cornea, and glaucoma) had fewer missed clinic visits. This was seen internationally with a decrease in corneal transplants in Italy and a decrease in cataract surgeries in London. ${ }^{7,8}$ Recognition of the potential for harm from missed visits may have offset the perceived risk of COVID-19 transmission. We were surprised to find that missed visit rates between new and returning patients were remarkably similar.

Female patients had higher adjusted odds of missing visits, both pre-COVID-19 (13\% greater than males) and during COVID-19 (23\% greater than males). The higher rate of missed visits in women is concerning given their historically 
Table 2 Multivariable Logistic Regression for Odds of Missing at Least One Scheduled Clinic Visit During Pre-COVID-19 and COVID19 Time Periods

\begin{tabular}{|c|c|c|c|c|c|}
\hline & \multicolumn{2}{|c|}{ Pre-COVID-19 Time Period ${ }^{a}$} & \multicolumn{2}{|l|}{ COVID-19 Time Period } & \multirow{2}{*}{$\begin{array}{l}\text { Significance of } \\
\text { Interaction } \\
\text { with Time } \\
\text { Period (pre- } \\
\text { COVID-19 vs } \\
\text { COVID)c } \\
\text { p-value }\end{array}$} \\
\hline & Odds Ratio (95th Cl) & p-value & Odds Ratio (95th Cl) & p-value & \\
\hline Female $($ Ref $=$ Male $)$ & $1.13(1.04-1.24)$ & 0.004 & $1.23(1.15-1.32)$ & $<0.001$ & 0.166 \\
\hline \multicolumn{6}{|l|}{ Race (Ref=White) } \\
\hline Black & $1.76(1.37-2.27)$ & $<0.001$ & $1.51(1.21-1.88)$ & $<0.001$ & 0.356 \\
\hline Asian & $1.25(1.12-1.40)$ & $<0.001$ & $\mathrm{I} .67(\mathrm{I} .52-\mathrm{I} .83)$ & $<0.001$ & $<0.001$ \\
\hline Hispanic & $1.03(0.89-1.19)$ & 0.670 & $1.31(1.17-1.46)$ & $<0.001$ & 0.011 \\
\hline Other & $1.35(1.17-1.55)$ & $<0.001$ & $1.41(1.26-1.58)$ & $<0.001$ & 0.618 \\
\hline \multicolumn{6}{|l|}{ Age (Ref $=<50$ years) } \\
\hline $50-64$ years & $1.76(1.55-1.99)$ & $<0.001$ & $2.13(1.92-2.36)$ & $<0.001$ & 0.021 \\
\hline $65-74$ years & $1.5(1.28-1.76)$ & $<0.001$ & $2.29(2.01-2.60)$ & $<0.001$ & $<0.001$ \\
\hline $75-84$ years & $1.26(1.05-1.52)$ & 0.013 & $2.31(1.99-2.68)$ & $<0.001$ & $<0.001$ \\
\hline$\geq 85$ years & $1.21(0.96-1.53)$ & 0.111 & $2.62(2.17-3.15)$ & $<0.001$ & $<0.001$ \\
\hline $\begin{array}{l}\text { English preferred language } \\
\text { (Ref=Non-English } \\
\text { preferred language) }\end{array}$ & $0.86(0.76-0.98)$ & 0.019 & $1.12(1.01-1.25)$ & 0.036 & 0.002 \\
\hline $\begin{array}{l}\text { Married }(\text { Ref }=\text { Not } \\
\text { married) }\end{array}$ & $1.07(0.97-1.18)$ & 0.160 & $1.39(1.28-1.50)$ & $<0.001$ & $<0.001$ \\
\hline DME (Ref=no DME) & $0.88(0.64-1.2 \mathrm{I})$ & 0.424 & $0.77(0.61-0.98)$ & 0.032 & 0.527 \\
\hline $\begin{array}{l}\text { Wet AMD }(\text { Ref }=\text { no wet } \\
\text { AMD) }\end{array}$ & $1.34(1.01-1.78)$ & 0.046 & $0.72(0.57-0.91)$ & 0.005 & 0.001 \\
\hline $\begin{array}{l}\text { Dry AMD (Ref=no dry } \\
\text { AMD) }\end{array}$ & $1.07(0.87-1.32)$ & 0.515 & 1.25 (1.07-1.47) & 0.006 & 0.248 \\
\hline $\begin{array}{l}\text { Cataract (ref = no } \\
\text { cataract) }\end{array}$ & $1.18(1.04-1.34)$ & 0.011 & $1.73(1.56-1.91)$ & $<0.001$ & $<0.001$ \\
\hline $\begin{array}{l}\text { Pseudophakia/Aphakia } \\
\text { (Ref=no pseudophakia or } \\
\text { aphakia) }\end{array}$ & $1.06(0.90-1.25)$ & 0.500 & $1.3(1.15-1.48)$ & $<0.001$ & 0.052 \\
\hline $\begin{array}{l}\text { Pathologic Myopia } \\
\text { (Ref=no pathologic } \\
\text { myopia) }\end{array}$ & $0.93(0.72-1.20)$ & 0.579 & 1.47 (1.22-1.77) & $<0.001$ & 0.004 \\
\hline Multiple diagnoses & $0.96(0.77-1.20)$ & 0.722 & $0.81(0.69-0.95)$ & 0.011 & 0.214 \\
\hline
\end{tabular}

(Continued) 
Table 2 (Continued).

\begin{tabular}{|c|c|c|c|c|c|}
\hline & \multicolumn{2}{|c|}{ Pre-COVID-19 Time Period ${ }^{a}$} & \multicolumn{2}{|c|}{ COVID-19 Time Period ${ }^{b}$} & \multirow{2}{*}{$\begin{array}{l}\text { Significance of } \\
\text { Interaction } \\
\text { with Time } \\
\text { Period (pre- } \\
\text { covID-19 vs } \\
\text { covID) }\end{array}$} \\
\hline & Odds Ratio (95th Cl) & p-value & Odds Ratio (95th Cl) & p-value & \\
\hline \multicolumn{6}{|l|}{ Glaucoma } \\
\hline Unspecified glaucoma & $0.97(0.70-1.35)$ & 0.865 & $0.98(0.76-1.26)$ & 0.868 & 0.973 \\
\hline Mild glaucoma & $0.91(0.66-1.27)$ & 0.595 & $1.23(0.98-1.55)$ & 0.079 & 0.150 \\
\hline Moderate glaucoma & $0.79(0.60-1.05)$ & 0.108 & $0.93(0.76-1.14)$ & 0.482 & 0.362 \\
\hline Severe glaucoma & $0.98(0.76-1.27)$ & 0.875 & $0.94(0.77-1.13)$ & 0.492 & 0.777 \\
\hline \multicolumn{6}{|l|}{ Diabetic retinopathy } \\
\hline Mild & $0.98(0.60-1.59)$ & 0.929 & $1.58(1.12-2.22)$ & 0.009 & 0.115 \\
\hline Moderate & $0.66(0.30-1.46)$ & 0.308 & $0.91(0.58-1.45)$ & 0.705 & 0.491 \\
\hline Severe & $1.47(0.65-3.36)$ & 0.358 & $1.17(0.60-2.28)$ & 0.640 & 0.673 \\
\hline Proliferative & $1.39(0.91-2.12)$ & 0.130 & $1.08(0.78-1.50)$ & 0.647 & 0.359 \\
\hline \multicolumn{6}{|c|}{ Distance from Clinic $(r e f=<20 \mathrm{~km})$} \\
\hline $20-49 \mathrm{~km}$ & $1.14(1.02-1.28)$ & 0.017 & $0.97(0.89-1.06)$ & 0.555 & 0.025 \\
\hline $50-149 \mathrm{~km}$ & $1.23(1.08-1.40)$ & 0.002 & $0.92(0.83-1.02)$ & 0.121 & 0.001 \\
\hline $150-299 \mathrm{~km}$ & $1.32(1.09-1.61)$ & 0.005 & $1.01(0.86-1.19)$ & 0.889 & 0.038 \\
\hline$>300 \mathrm{~km}$ & $1.43(1.14-1.81)$ & 0.002 & $1.16(0.96-1.42)$ & 0.131 & 0.178 \\
\hline \multicolumn{6}{|c|}{ Insurance (Ref=private insurance) } \\
\hline Medicare & $0.93(0.8 \mathrm{I}-1.07)$ & 0.334 & $1.05(0.94-1.17)$ & 0.399 & 0.200 \\
\hline Medicaid & $0.8(0.69-0.92)$ & 0.003 & $0.8(0.7 I-0.89)$ & $<0.00 \mathrm{I}$ & 0.959 \\
\hline Other insurance & $1.23(0.89-1.7 \mathrm{I})$ & 0.208 & $1.16(0.87-1.54)$ & 0.310 & 0.778 \\
\hline \multicolumn{6}{|c|}{ Household Income (Ref $=<\$ 20,000)$} \\
\hline$\$ 20,000-\$ 49,999$ & $0.92(0.82-1.04)$ & 0.188 & $1.0(0.91-1.10)$ & 0.919 & 0.276 \\
\hline$\$ 50,000-\$ 99,999$ & $1.0(0.87-1.14)$ & 0.965 & $1.0(0.90-1.11)$ & 0.999 & 0.974 \\
\hline$\$ 100,000+$ & $0.9(0.74-I .1 I)$ & 0.328 & $0.93(0.79-1.09)$ & 0.351 & 0.860 \\
\hline
\end{tabular}

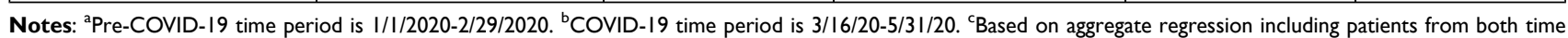
periods, with an independent variable for time period (pre-COVID-19 vs COVID-19). This statistic represents the p-value indicating level of statistical significance for an interaction term with each listed covariate and the time-period variable.

Abbreviations: DME, diabetic macular edema; AMD, age-related macular degeneration; $\mathrm{Cl}$, confidence interval.

higher rates of visual impairment, ${ }^{21}$ although we did not confirm greater female visual impairment in our study population. We speculate that these findings may reflect factors such as additional child care responsibilities, caregiving responsibilities, and/or lack of a caregiver to assist with visit reminders and transportation since women are more likely to survive their spouses and live alone. ${ }^{22,23}$ Of note, however, married patients had higher odds of missed visits both before COVID19 (7\% higher) and during COVID-19 (39\% higher), perhaps reflecting competing family responsibilities. 
One of the most striking findings in our analysis points to racial/ethnic disparities. White patients had the lowest adjusted odds of missed visits both before COVID-19 and during COVID-19. Before COVID-19, Blacks had the highest odds of missed visits ( $76 \%$ greater than whites), likely reflecting well-documented impaired access to care in multiple domains. ${ }^{24,25}$ While Asians had only $25 \%$ higher adjusted odds of missed visits compared to white patients before COVID-19, they had the highest odds (67\% greater than white patients) during COVID-19. We speculate that the greater prevalence of missed visits among Asians may have reflected cultural differences, more risk-averse behavior, and/or fear of encountering racism during the early months of the pandemic.

Prior to COVID-19, patients aged 50-64 years had the highest adjusted odds of missed visits $(76 \%$ higher adjusted odds compared to patients 50 years old or younger) and patients over age 75 years had approximately $20 \%$ greater adjusted odds of missed visits compared to those 50 years or younger. During COVID-19, however, the adjusted odds of missed visits were highest for patients over age 75 years (over 2-fold increased odds), presumably reflecting heightened concern for greater COVID-19associated morbidity and mortality in older populations. ${ }^{26}$ Notably, our pre-COVID-19 results are inconsistent with prior studies in other specialties, which found that younger adults had higher rates of missed visits. ${ }^{27}$ Older patients' increased odds of missing visits along with their generally more severe morbidity from age-related eye diseases such as AMD and glaucoma, points to the importance of targeting older adult populations for safe access to care.

We also observed an interesting trend based on the distance between a patient's residential zip code and Byers Eye Center. Before COVID-19, patients residing further from the clinic had higher adjusted odds of missed visits - those 150-299 $\mathrm{km}$ and $\geq 300 \mathrm{~km}$ away had $32 \%$ and $43 \%$ higher odds, respectively, consistent with one previous report. ${ }^{27}$ During COVID-19, however, we saw no significant difference with respect to distance. To what degree this leveling of distance effect on missed visits was due to decreased traffic easing more distant patients' commutes, stricter shelter-in-place orders in the counties closest to the clinic, or differences in ocular pathology and urgency of care will be difficult to differentiate but could be evaluated in similar analyses conducted at other centers in the future.

While many studies have found that underinsured patients generally have higher missed visit rates, ${ }^{28-30}$ we found that patients with Medicaid and other non-private insurances did not have significantly different odds of missed visits pre-COVID-19. Furthermore, patients with Medicaid had lower odds of missed visits during COVID19. These differences may reflect our model accounting for additional confounders, and/or other regional factors which lower the burden of health-care utilization among underinsured patients.

Among common ophthalmic diagnoses evaluated in our analysis, wet AMD patients had 34\% higher adjusted odds of missed visits before COVID-19, but lower adjusted odds during COVID-19 (compared to patients without wet AMD). This is similar to our clinical specialty analysis, which found lower frequency of missed visits in retina clinics and is consistent with wet AMD patients requiring intravitreal injections as often as every month to prevent irreversible vision loss. Interestingly, we did not find that patients coded with severe glaucoma or diabetic retinopathy had significantly different odds of missed visits compared to patients with mild disease, despite the fact that more severe pathology generally requires more frequent monitoring and intervention. These data may reflect challenges in communicating disease severity and compliance with treatment, ${ }^{31-33}$ and they reinforce the need to educate patients more explicitly about relative risk.

Our study was limited to a single center, which may affect generalizability, particularly as the severity, timing, and the response to the pandemic varied across different regions. Additionally, our pre-COVID-19 (Jan-Feb 2020) time period could be confounded by very early behavioral changes from COVID-19 publicity regarding outbreaks abroad and our COVID-19 (Mar-May 2020) time period focuses on the first local wave of the pandemic. Our COVID-19 time period does, however, correlate with the strictest lockdown period. We also used structured diagnosis codes, which inherently can contain errors. Although we manually reviewed patients' stated reasons for missed visits, in some cases these reasons were ambiguous and could not be attributed specifically to COVID-19 or nonCOVID-19 related reasons. We were also unable to reliably distinguish patient-cancelled from provider-cancelled /provider-recommended missed visits. However, although the institution did restrict elective surgeries during our study period - which may have affected missed visits for patients who had planned preoperative appointments for cataract, for example - there was no department or hospital-based policy for deferral of clinic appointments during this time (instead relying on implementation of safety 
measures and conversion of face-to-face to telehealth visits where appropriate, which we included as completed appointments in our analysis). Finally, our study analyzes health-care utilization but does not trend outcomes and additional research will be needed to see the impact of decreased health-care utilization during the first two months of the COVID-19 pandemic on visual outcomes.

Future studies should analyze the impact of missed visits on long-term visual outcomes of ophthalmology patients. For example, it is important to determine whether patients who missed scheduled monthly anti-Vascular Endothelial Growth Factor (anti-VEGF) injections for wet AMD consequently lost central visual acuity, or whether glaucoma patients were more likely to progress, perhaps in association with decreased adherence to clinic visits, monitoring, and/or medication refills. Additionally, the impact of COVID-19 on elective and urgent ophthalmic surgeries is an important future area of study, for example, to identify whether delaying surgery affected patients' quality of life, driving ability, or fall risk. ${ }^{34,35}$ The increase in missed visit rates for any patient with a diagnosis causing visual impairment should raise concern, as visual impairment is linked to an increase in falls and depression and a decrease in independent living and obtaining employment. $^{36-39}$

In conclusion, these data illuminate differences in the prioritization of and access to eye care during the pandemic. Our findings should inform physicians, hospital administrators, and public health authorities on the patients most likely to miss visits both before and during the COVID-19 period, thereby revealing opportunities to address health-care disparities during and after the pandemic.

\section{Disclosure}

Dr Suzann Pershing is a consultant for Acumen LLC, served as a consultant for and owed equity interest from Digisight Technologies, and reports grants from NIH, outside the submitted work. The authors report no other conflicts of interest in this work.

\section{References}

1. Parke DW 2nd. Ophthalmology after Coronavirus disease 2019 (COVID-19): transition back to patient care. JAMA Ophthalmol. 2020;138:599-600. doi:10.1001/jamaophthalmol.2020.2004

2. Kuo IC, O'Brien TP. COVID-19 and ophthalmology: an environmental work hazard. J Occup Health. 2020;62:e12124. doi:10.1002/13489585.12124
3. Birkmeyer JD, Barnato A, Birkmeyer N, et al. The impact of the COVID-19 pandemic on hospital admissions in the United States. Health Aff. 2020;39:2010-2017. doi:10.1377/hlthaff.2020.00980

4. Jain A, Dai T, Bibee K, Myers CG. Covid-19 created an elective surgery backlog. How can hospitals get back on track. Harvard Business Review; 2020. Available from: https://hbr.org/2020/08/ covid-19-created-an-elective-surgery-backlog-how-can-hospitals-getback-on-track. Accessed September 28, 2020.

5. Anon. Recommendations for urgent and nonurgent patient care. Accessed. American Academy of Ophthalmology; 2020. Available from: https://www.aao.org/headline/new-recommendations-urgentnonurgent-patient-care. Accessed December 16, 2020.

6. Anon. Analysis: ophthalmology lost more patient volume due to COVID-19 than any other specialty. Eyewire News; 2020. Available from: https://eyewire.news/articles/analysis-55-percentfewer-americans-sought-hospital-care-in-march-april-due-to-covid -19/. Accessed September 28, 2020.

7. Aiello F, Genzano Besso F, Pocobelli G, et al. Corneal transplant during COVID-19 pandemic: the Italian Eye Bank national report. Cell Tissue Bank. 2021;22:697-702. doi:10.1007/s10561-02109934-8

8. Tee JJL, Al-Hayouti H, Masih M, et al. Moorfields cataract surgery recovery pilot during the Covid-19 pandemic. Eye. 2021. doi:10.1038/s41433-020-01310-2

9. Hutton D. Should ophthalmologists prepare for a second surge? Ophthalmology Times; 2020. Available from: https://www.ophthalmo logytimes.com/view/covid-19-should-ophthalmologists-prepare-for -a-second-surge. Accessed September 28, 2020.

10. Fu SJ, George EL, Maggio PM, et al. The consequences of delaying elective surgery: surgical perspective. Ann Surg. 2020;272:e79-e80. doi:10.1097/SLA.0000000000003998

11. Tai DBG, Shah A, Doubeni Ca, et al. The disproportionate impact of COVID-19 on racial and ethnic minorities in the United States. Clin Infect Dis. 2020. doi:10.1093/cid/ciaa815

12. Li J-PO, Shantha J, Wong TY, et al. Preparedness among ophthalmologists: during and beyond the COVID-19 pandemic. Ophthalmology. 2020;127:569-572. doi:10.1016/j. ophtha.2020.03.037

13. Bacherini D, Biagini I, Lenzetti C, et al. The COVID-19 pandemic from an ophthalmologist's perspective. Trends Mol Med. 2020;26:529-531. doi:10.1016/j.molmed.2020.03.008

14. Anon. Order of the health officer of the County of Santa Clara. SCCGOV; 2020. Available from: https://www.sccgov.org/sites/ covid19/Pages/order-health-officer-031620.aspx\#: :text=This\% 20 Order $\% 20$ shall $\% 20$ become $\% 20$ effective, writing $\% 20$ by $\% 20$ the $\%$ 20Health\%20Officer. Accessed December 13, 2020.

15. Anon. Covid 19 CA. ORDER OF THE STATE PUBLIC HEALTH OFFICER. Available from: https://www.gov.ca.gov/wp-content /uploads/2020/03/3.19.20-attested-EO-N-33-20-COVID-19-

HEALTH-ORDER.pdf. Accessed December 16, 2020.

16. Anon. Covid-19 timeline surgery stanford. Stanford Medicine | surgery. Available from: https://surgery.stanford.edu/news2/ COVID19-timeline.html. Accessed December 16, 2020.

17. Anon. STARR (aka STRIDE-web) tools home page. STARR. Available from: https://med.stanford.edu/starr-tools.html. Accessed December 10, 2020.

18. Anon. Google maps documentation. Available from: https://develo pers.google.com/maps/documentation. Accessed December 20, 2020.

19. Anon. ZIP code data - Internal Revenue Service. Available from: https:// www.irs.gov/pub/irs-soi/18zpdoc.docx. Accessed December 10, 2020.

20. Nanda T, Wang A, Ducasse LM, et al. No-show rates and associated patient factors in an ophthalmology resident practice. Nepal J Ophthalmol. 2020;12:e67-e73.

21. Abou-Gareeb I, Lewallen S, Bassett K, Courtright P. Gender and blindness: a meta-analysis of population-based prevalence surveys. Ophthalmic Epidemiol. 2001;8:39-56. doi:10.1076/opep.8.1.39.1540 
22. Kofman E, England K. Who will mind the baby? Geographies of child care and working mothers. Geogrl J. 1998;164:102. doi: $10.2307 / 3060559$

23. Stepler R. Smaller Share of Women Ages 65 and Older are Living Alone: More are Living with Spouse or Children. Pew Research Center; 2016.

24. Charron-Chénier R, Mueller CW. Racial disparities in medical spending: healthcare expenditures for black and white households (20132015). Race Soc Probl. 2018;10:113-133. doi:10.1007/s12552-0189226-4

25. Anderson KF, Fullerton AS. Racial residential segregation and access to health-care coverage: a multilevel analysis. Res Sociol Health Care. 2012;133-158. doi:10.1108/s0275-4959(2012)0000030009

26. Kang SJ, Jung SI. Age-related morbidity and mortality among patients with COVID-19. Infect Chemother. 2020;52:154-164. doi:10.3947/ic.2020.52.2.154

27. Dantas LF, Fleck JL, Cyrino Oliveira FL, Hamacher S. No-shows in appointment scheduling - a systematic literature review. Health Policy (New York). 2018;122:412-421. doi:10.1016/j.healthpol.2018.02.002

28. Moore CG, Wilson-Witherspoon P, Probst JC. Time and money: effects of no-shows at a family practice residency clinic. Fam Med. 2001;33:522-527.

29. Daggy J, Lawley M, Willis D, et al. Using no-show modeling to improve clinic performance. Health Informatics J. 2010;16:246-259. doi:10.1177/1460458210380521

30. Weingarten N, Meyer DL, Schneid JA. Failed appointments in residency practices: who misses them and what providers are most affected? J Am Board Fam Pract. 1997;10:407-411.

31. Taylor SA, Galbraith SM, Mills RP. Causes of non-compliance with drug regimens in glaucoma patients: a qualitative study. $J$ Ocul Pharmacol Ther. 2002;18:401-409. doi:10.1089/ 10807680260362687
32. Kosoko O, Quigley HA, Vitale S, et al. Risk factors for noncompliance with glaucoma follow-up visits in a residents' eye clinic. Ophthalmology. 1998;105:2105-2111. doi:10.1016/s0161-6420(98)91134-4

33. Chen AJ, Hwang V, Law PY, et al. Factors associated with non-compliance for diabetic retinopathy follow-up in an urban safety-net hospital. Ophthalmic Epidemiol. 2018;25:443-450. doi:10.1080/09286586.2018.1504311

34. Harwood RH, Foss AJE, Osborn F, et al. Falls and health status in elderly women following first eye cataract surgery: a randomised controlled trial. Br J Ophthalmol. 2005;89:53-59. doi:10.1136/ bjo.2004.049478

35. Mennemeyer ST, Owsley C, McGwin G. Reducing older driver motor vehicle collisions via earlier cataract surgery. Accid Anal Prev. 2013;61:203-211. doi:10.1016/j.aap.2013.01.002

36. Nastasi JA. The everyday lives of older adults with visual impairment: an occupational perspective. $\mathrm{Br} J$ Occup Ther. 2018;81:266-275. doi:10.1177/0308022617752093

37. Renaud J, Bédard E. Depression in the elderly with visual impairment and its association with quality of life. Clin Interv Aging. 2013;8:931. doi: $10.2147 /$ cia.s27717

38. Swagerty DL Jr. The impact of age-related visual impairment on functional independence in the elderly. Kans Med. 1995;96:24-26.

39. O'Day B. Employment barriers for people with visual impairments. $J \quad$ Vis Impair Blind. 1999;93:627-642. doi:10.1177/ 0145482X9909301002
Clinical Ophthalmology

\section{Publish your work in this journal}

Clinical Ophthalmology is an international, peer-reviewed journal covering all subspecialties within ophthalmology. Key topics include: Optometry; Visual science; Pharmacology and drug therapy in eye diseases; Basic Sciences; Primary and Secondary eye care; Patient Safety and Quality of Care Improvements. This journal is indexed on PubMed
Dovepress

Central and CAS, and is the official journal of The Society of Clinical Ophthalmology (SCO). The manuscript management system is completely online and includes a very quick and fair peer-review system, which is all easy to use. Visit http://www.dovepress.com/ testimonials.php to read real quotes from published authors. 